\title{
Early adaptive immune activation detected in monozygotic twins with prodromal multiple sclerosis
}

\author{
Eduardo Beltrán, ${ }^{1}$ Lisa Ann Gerdes, ${ }^{1}$ Julia Hansen, ${ }^{1}$ Andrea Flierl-Hecht, ${ }^{1}$ Stefan Krebs, ${ }^{2}$ Helmut Blum, ${ }^{2}$ Birgit Ertl-Wagner, ${ }^{3,4}$ \\ Frederik Barkhof, ${ }^{5,6}$ Tania Kümpfel, ${ }^{1}$ Reinhard Hohlfeld, ${ }^{1,7}$ and Klaus Dornmair ${ }^{1,7}$ \\ IInstitute of Clinical Neuroimmunology, Biomedical Center and Hospital; ${ }^{2}$ Laboratory for Functional Cenome Analysis (LAFUGA), Gene Center; and ${ }^{3}$ Department of Radiology, Grosshadern Medical Campus; \\ Ludwig Maximilian University of Munich, Munich, Germany. ${ }^{4}$ Department of Medical Imaging, The Hospital for Sick Children, University of Toronto, Toronto, Ontario, Canada. ${ }^{5}$ Department of Radiology and

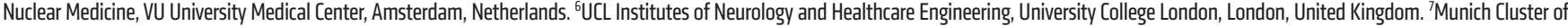 \\ Systems Neurology (SyNergy), Munich, Germany.
}

\begin{abstract}
Multiple sclerosis (MS) is a disabling disease of the CNS. Inflammatory features of MS include lymphocyte accumulations in the CNS and cerebrospinal fluid (CSF). The preclinical events leading to established MS are still enigmatic. Here we compared gene expression patterns of CSF cells from MS-discordant monozygotic twin pairs. Six "healthy" co-twins, who carry a maximal familial risk for developing MS, showed subclinical neuroinflammation (SCNI) with small MRI lesions. Four of these subjects had oligoclonal bands (OCBs). By single-cell RNA sequencing of 2752 CSF cells, we identified clonally expanded CD8 ${ }^{+} \mathrm{T}$ cells, plasmablasts, and, to a lesser extent, CD4+ $\mathrm{T}$ cells not only from MS patients but also from subjects with SCNI. In contrast to nonexpanded T cells, clonally expanded T cells showed characteristics of activated tissue-resident memory $T\left(T_{R M}\right)$ cells. The $T_{R M}$-like phenotype was detectable already in cells from SCNI subjects but more pronounced in cells from patients with definite MS. Expanded plasmablast clones were detected only in MS and SCNI subjects with OCBs. Our data provide evidence for very early concomitant activation of 3 components of the adaptive immune system in MS, with a notable contribution of clonally expanded $\mathrm{T}_{\mathrm{RM}}$-like $\mathrm{CD8} 8^{+}$cells.
\end{abstract}

\section{Introduction}

Multiple sclerosis (MS) is the most frequent inflammatory disease of the central nervous system (CNS). A variety of lymphocyte subtypes invade the brain parenchyma, where they sustain chronic inflammation and contribute to characteristic lesion formation. The current concepts of MS pathogenesis and treatment have been mainly shaped by autoimmune animal models, with a strong emphasis on autoreactive CD $4^{+} \mathrm{T}$ effector lymphocytes (1-4). In contrast to animal models, it has been difficult to investigate the early phase of the disease process in humans, because the diagnosis of MS requires the occurrence of a first clinical episode, which is known to be preceded by an undetermined period of subclinical neuroinflammation. It has therefore been very difficult to distinguish between early, potentially primary, and later, potentially secondary, immunological mechanisms.

Here we took a 2-pronged approach to investigate the earliest identifiable stages of MS, which we refer to as subclinical neuroinflammation (SCNI), in familially predisposed subjects. First, we identified a small cohort of monozygotic twins in whom one sibling has clinically definite MS and the other is clinically "healthy" but has MRI and/or immunological evidence for SCNI. Second, we

Authorship note: EB, LAG, and JH are co-first authors. RH and KD are co-senior authors. Conflict of interest: The authors have declared that no conflict of interest exists. Copyright: (c) 2019, American Society for Clinical Investigation.

Submitted: February 27, 2019; Accepted: August 1, 2019; Published: September 30, 2019 Reference information: J Clin Invest. 2019;129(11):4758-4768.

https://doi.org/10.1172/JCl128475. applied single-cell whole transcriptome sequencing (scRNA-Seq) to analyze cerebrospinal fluid (CSF) samples from MS-discordant twin pairs and controls. In contrast to traditional flow cytometry, which is restricted to very limited panels of antibodies against preselected markers, this technology gives an unbiased overview of expression patterns of thousands of genes expressed in each single cell at the time of lumbar puncture. This technology offers novel insights into the complexities of the human immune system and of disease-relevant cell populations $(5,6)$.

We found that clonal expansions of $\mathrm{CD}^{+} \mathrm{T}$ cells, $\mathrm{B}$ cells, and $\mathrm{CD} 4^{+} \mathrm{T}$ cells are conspicuous even in the prodromal stage of MS in familially predisposed subjects. Strikingly, the majority of clonal expansions occur in the $\mathrm{CD} 8^{+} \mathrm{T}$ cell compartment. In direct comparison with nonexpanded $\mathrm{CD} 8^{+} \mathrm{T}$ cells, the clonally expanded $\mathrm{CD} 8^{+} \mathrm{T}$ cells show distinct signs of acute activation, express an array of cytotoxic effector molecules, and phenotypically resemble tissue-resident memory $\mathrm{T}\left(\mathrm{T}_{\mathrm{RM}}\right)$ cells $(7,8)$. This pattern was most pronounced in subjects with definite MS, less pronounced but detectable in subjects with SCNI, and absent in healthy controls and nonexpanded cells from all subjects. In the $\mathrm{CD} 4^{+}$compartment, a few clonal expansions are present, which also display an activated phenotype. Furthermore, the presence of clonally expanded B cells in the plasmablast cluster is strictly correlated with the presence of oligoclonal immunoglobulin bands (OCBs). Viewed together, our findings demonstrate that even the earliest experimentally approachable stage of MS is characterized by a synergistic activation of the main components of the adaptive immune system, with a striking contribution of recently activated, clonally expanded $\mathrm{CD} 8^{+} \mathrm{T}$ cells with a $\mathrm{T}_{\mathrm{RM}}$ phenotype. 
A

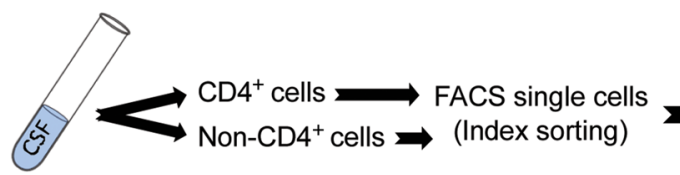

B

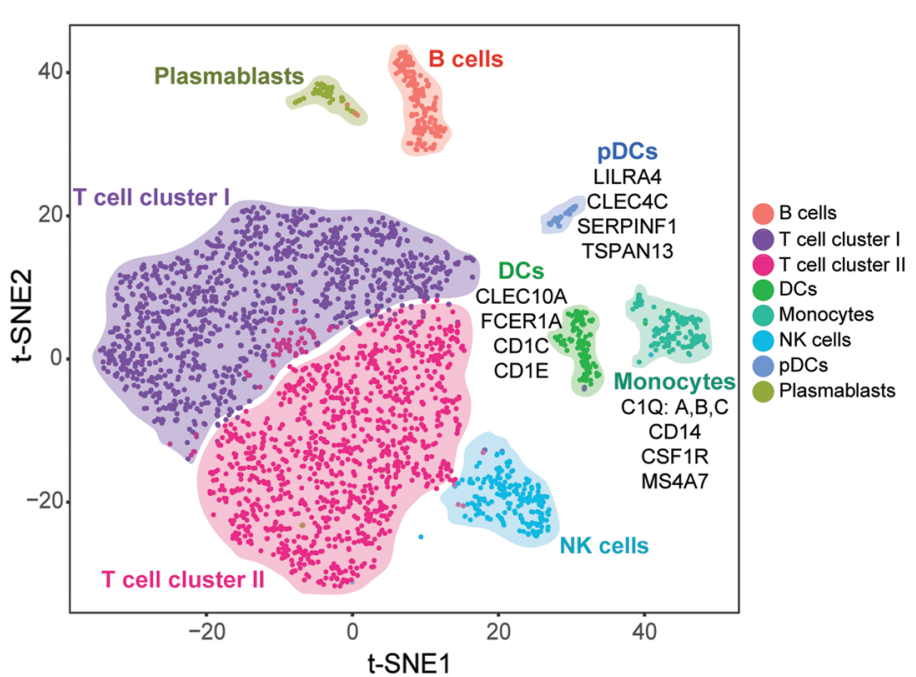

C T cell cluster I T cell cluster II

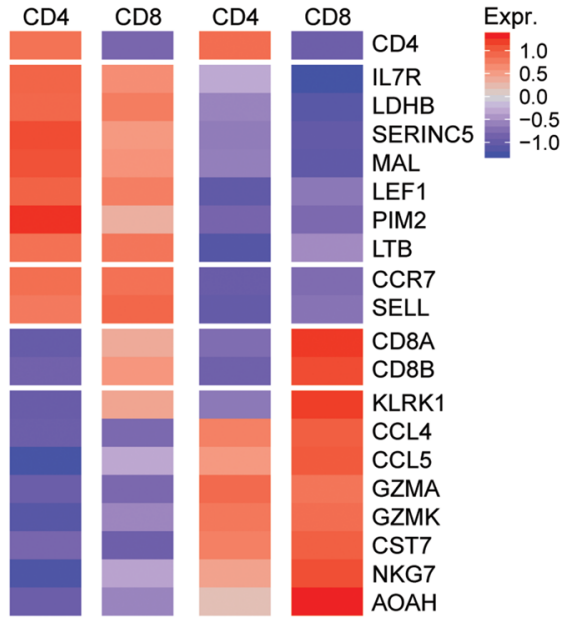

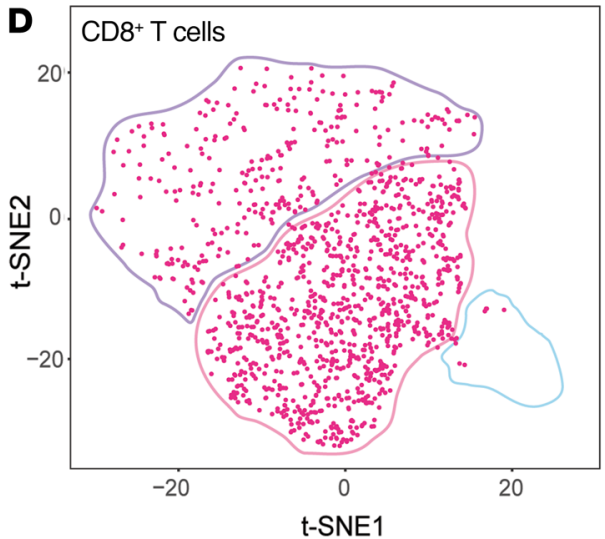

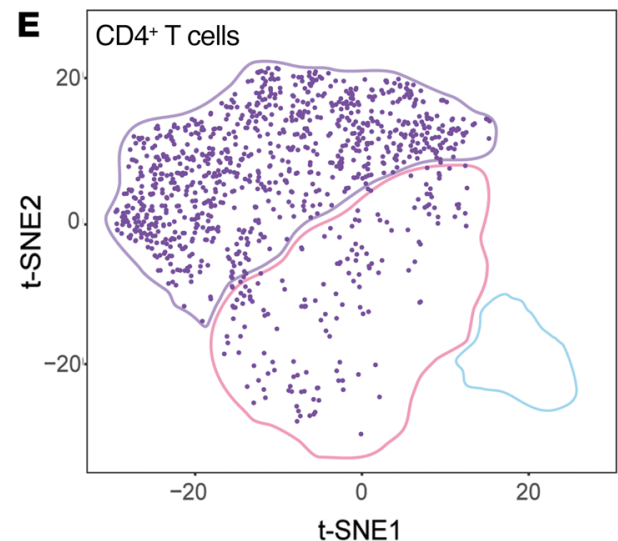

Figure 1. Cellular composition of lymphocytes upon analysis by scRNA-Seq. (A) Flowchart of the analysis of human CSF by scRNA-Seq. Because CD4+ cells make up the majority of CSF cells, they were collected by magnetic beads and single CD4+ cells were isolated by flow cytometry. The remaining non-CD4 ${ }^{+}$ cells were separately isolated by single-cell index sorting using different markers. Thus, the ratio of $\mathrm{CD} 4^{+}$and non-CD4+ ${ }^{+}$cell numbers does not reflect the ratio of absolute cell numbers in the CSF samples. Nevertheless, ratios and cell numbers within the non-CD4+ populations are comparable. Whole transcriptomes of each single cell were determined by next-generation sequencing (NGS) with a read length of $2 \times 150$ bp that allows identification of the hypervariable regions of TCRs and BCRs together with their corresponding $V$ families. Thus, not only transcriptome profiles of each single cell are determined, but also matching $\alpha: \beta$ TCR and H:L BCR chains. This allows tracking of distinct clones. (B) t-SNE projection of transcriptome data from 2752 single CSF cells and 332 PBMCs from 16 patients, profiled in 9 main clusters. For better visualization, background areas were shaded manually to indicate major cell populations, although some cells will appear in "foreign" areas. Each dot corresponds to one single cell, colored according to the respective cell cluster. DCs, pDCs, and monocytes were not specifically labeled during flow cytometry analyses; therefore up to 6 transcripts were used as discriminators and are listed next to each cluster. (C) Heatmap showing normalized mean expression levels of discriminative gene sets for T cell cluster I CD4+ (lane 1 ) and CD8 $8^{+}$cells (lane 2), and cluster II CD4+ (Iane 3) and CD8 ${ }^{+}$cells (lane 4). (D) t-SNE projection of all index-sorted CD8 ${ }^{+}$T cells. (E) t-SNE projection of all index-sorted CD4 ${ }^{+}$T cells.

\section{Results}

Landscape of lymphocytes analyzed by scRNA-Seq. To obtain an overview of the different lymphocyte populations, we isolated single lymphocytes by flow cytometry, determined their transcriptomes by scRNA-Seq, and applied dimensional reduction analysis (t-distributed stochastic neighbor embedding [t-SNE]) to the gene expression data (see Figure 1A for workflow). Altogether, we analyzed 3084 single lymphocyte cells from 16 subjects (Figure 1B and Table 1). We spiked 2752 CSF cells with 332 cells from peripheral blood, since blood cells are well characterized; these cells served as "guideposts" to initially match the unbiased clustering to known immune cell types. In all subsequent analyses, blood cells were excluded from the data set. Throughout, we used conditions that allowed us to identify distinct $\mathrm{T}$ and $\mathrm{B}$ cell clones 
Table 1. Clinical characteristics of all subjects

\begin{tabular}{|c|c|c|c|c|c|c|c|c|c|}
\hline & Code & Disease type & Age & Sex & $\begin{array}{c}\text { Time interval of disease discordance/ } \\
\text { disease duration (yr) }\end{array}$ & $\begin{array}{l}\text { Disease-modifying } \\
\text { treatment }\end{array}$ & MRI findings & CSF results & EDSS score \\
\hline \multirow[t]{2}{*}{ Twin pair } & AR-MS & RRMS & 40 & $\mathrm{~F}$ & 4.0 & IFN- $\beta$ & $>5 W_{M L s^{A, B}}$ & $\mathrm{OCB}^{+}, 2 / \mu \mathrm{L}$ & 1.5 \\
\hline & AR-H & SCNI & 40 & $\mathrm{~F}$ & 4.0 & None & $>5 W M L s^{A}$ & $\mathrm{OCB}+5 / \mu \mathrm{L}$ & 0.0 \\
\hline \multirow[t]{2}{*}{ Twin pair } & AU-MS & RRMS & 21 & $\mathrm{~F}$ & 1.5 & Natalizumab & $>5 W M L s^{A}$ & $\mathrm{OCB}+3 / \mu \mathrm{L}$ & 2.0 \\
\hline & $\mathrm{AU}-\mathrm{H}$ & SCNI & 21 & $\mathrm{~F}$ & 1.5 & None & 2-5 WMLs & $\mathrm{OCB}+13 / \mu \mathrm{L}$ & 0.0 \\
\hline \multirow[t]{2}{*}{ Twin pair } & AV-MS & SPMS & 50 & $\mathrm{~F}$ & 17.0 & Intrathecal steroids & $>5 W M L s^{A}$ & $\mathrm{OCB}-1 / \mu \mathrm{L}$ & 6.0 \\
\hline & AV-H & Healthy & 50 & $\mathrm{~F}$ & 17.0 & None & No WMLs & $\mathrm{OCB}-, 3 / \mu \mathrm{L}$ & 0.0 \\
\hline \multirow[t]{2}{*}{ Twin pair } & BJ-MS & RRMS & 45 & $\mathrm{~F}$ & 1.0 & Teriflunomide & $>5 W M L s^{A}$ & $O C B^{+}, 3 / \mu \mathrm{L}$ & 4.0 \\
\hline & $\mathrm{BJ}-\mathrm{H}$ & Healthy & 45 & $\mathrm{~F}$ & 1.0 & None & No WMLs & $\mathrm{OCB}-1 / \mu \mathrm{L}$ & 0.0 \\
\hline Co-twin & $\mathrm{BF}-\mathrm{H}$ & SCNI & 28 & $\mathrm{~F}$ & 1.5 & None & $2-5 W M L s^{A}$ & $\mathrm{OCB}+3 / \mu \mathrm{L}$ & 0.0 \\
\hline Co-twin & $\mathrm{V}-\mathrm{H}$ & SCNI & 38 & M & 7.0 & None & $1 \mathrm{WML}$ & $\mathrm{OCB}+9 / \mu \mathrm{L}$ & 0.0 \\
\hline Co-twin & $\mathrm{D}-\mathrm{H}$ & SCNI & 32 & $\mathrm{~F}$ & 13.0 & None & 2-5 WMLs & $\mathrm{OCB}^{-}, 2 / \mu \mathrm{L}$ & 0.0 \\
\hline Co-twin & W-H & SCNI & 69 & $\mathrm{~F}$ & 28.0 & None & $1 \mathrm{WML}$ & OCB-, $4 / \mu \mathrm{L}$ & 0.0 \\
\hline Enc & Enc-1 & LGI-1-E & 62 & M & 0.3 & Steroids, PLEX & No WMLs & OCB-, $3 / \mu \mathrm{L}$ & NA \\
\hline Enc & Enc-2 & NMDA-R-E & 20 & $\mathrm{~F}$ & 0.4 & Steroids, PLEX, RX, IVIG & 2-5 WMLs & $O C B^{-}, 1 / \mu \mathrm{L}$ & NA \\
\hline NIC & NIC-14 & IIH & 22 & $\mathrm{~F}$ & 1.0 & Acetazolamide & No WMLs & $O C B^{-}, 3 / \mu \mathrm{L}$ & NA \\
\hline NIC & NIC-15 & IIH & 30 & $\mathrm{~F}$ & 0.5 & Acetazolamide & No WMLs & $\mathrm{OCB}-3 / \mu \mathrm{L}$ & NA \\
\hline
\end{tabular}

Columns 1 and 2 list the subjects and their code numbers. Included are 4 clinically discordant monozygotic twin pairs, 4 co-twins with SCNI from whom CSF of the corresponding MS twin was not available, 2 subjects with encephalitis (anti-leucine-rich glioma inactivated 1 encephalitis [LGI-1-E] and anti-NMDA receptor encephalitis [NMDA-R-E]), and 2 NIC controls with intracranial idiopathic hypertension (IIH). The following columns list the type of disease, age, sex, time interval of discordance for MS (for discordant MS twin pairs) or disease duration, disease-modifying treatment, MRI findings, results of CSF diagnostics (OCBs and cell counts per microliter), and expanded disability status scale (EDSS) score. IVIG, intravenous immunoglobulins; OCB, oligoclonal bands; PLEX, plasma exchange; RRMS, relapsing remitting MS; RX, rituximab; SPMS, secondary progressive MS; WML, white matter lesion. ${ }^{\mathrm{A}}$ Dissemination in space with at least 2 lesions in 2 different regions according to the revised McDonald criteria (2017); ${ }^{B}$ dissemination in time with detection of new lesions in a follow-up MRI scan.

according to their matching $\mathrm{T}$ and $\mathrm{B}$ cell antigen receptor (TCR, BCR) chains (Figure 1A). After combining the gene markers for each individual cluster identified through unbiased clustering with the flow cytometry data, we grouped the cells into several clusters designated $\mathrm{T}$ cell cluster I, T cell cluster II, plasmablasts, B cells, plasmacytoid dendritic cells (pDCs), all other subfamilies of dendritic cells (DCs), monocytes, and natural killer (NK) cells (Figure 1B and Supplemental Table 1). Further, CD4 ${ }^{+}$and $\mathrm{CD}^{+}$ $\mathrm{T}$ cells were identified by the presence of at least one TCR chain as identified by scRNA-Seq. It should be noted that the absolute numbers of $\mathrm{CD} 4^{+}$cells do not reflect the relative proportion of sorted (analyzed) cells present in the original CSF samples (see legend to Figure $1 \mathrm{~A}$ ).

We then compared the expression profiles of genes that discriminate $\mathrm{T}$ cell clusters I and II (Figure 1C). The heatmap and corresponding t-SNE projections (Figure 1, D and E) show that $\mathrm{T}$ cell cluster I mainly (but not exclusively) contains CD $4^{+} \mathrm{T}$ cells, whereas $\mathrm{T}$ cell cluster II mainly contains $\mathrm{CD} 8^{+} \mathrm{T}$ cells. In each cluster, the dominant population expresses a characteristic panel of lead transcripts (e.g., IL-7 receptor in $\mathrm{CD}^{+} \mathrm{T}$ cells or cytotoxic molecules [granzymes] in $\mathrm{CD}^{+} \mathrm{T}$ cells). Further, each cluster contains a subpopulation of the nondominant phenotype $\left(\mathrm{CD} 8^{+}\right.$ cells in cluster I, CD $4^{+}$cells in cluster II). High levels of the chemokine receptor CCR7 and the cell adhesion molecule SELL confirm that cells profiled in $\mathrm{T}$ cell cluster I (mostly CD4 ${ }^{+}$) have a central memory $\left(\mathrm{T}_{\mathrm{CM}}\right)$ phenotype (9). In contrast, the mRNA profiles of discriminative genes of $\mathrm{T}$ cell cluster II (mostly $\mathrm{CD} 8^{+}$) suggest an effector/cytotoxic phenotype. In Figure 1, D and E, $\mathrm{TCR}^{+}$cells are displayed in accordance with their flow cytometry information as $\mathrm{CD} 8^{+}$or $\mathrm{CD}^{+}{ }^{+} \mathrm{T}$ cells.

Composition of CSF cell populations from SCNI, MS, and control subjects. Based on the overall cellular landscape determined by scRNA-Seq (Figure 1B), we compared the cellular distribution of CSF samples from 4 different groups of subjects: SCNI $(n=6)$, clinically definite MS (MS; $n=4)$, noninflammatory controls (NIC; $n=4$ ), and autoimmune encephalitis (Enc; $n=2$ ) (Figure 2, A-D, and Table 1). Our study cohort included 8 pairs of MS-discordant monozygotic twins. We were able to obtain CSF samples from all 8 clinically "healthy" co-twins, and from 4 of the MS-affected co-twins (Table 1). Among the 8 clinically healthy co-twins (who have a maximally high familial risk of developing MS), 6 subjects showed MRI evidence for SCNI. In addition, 4 of the 6 had OCBs (Table 1). None of the healthy co-twins had ever been treated with an immunosuppressive or immunomodulatory drug.

As seen in Figure 2, A-D, all groups show considerable similarities in the overall cellular distribution. In all groups, $\mathrm{T}$ cells contribute the majority of cells, and the distribution between $\mathrm{T}$ cell clusters I and II is preserved. B cells were also detectable in all groups, and plasmablasts were only missing in the NIC group. Notably, plasmablasts were already present in SCNI. When analyzing individual SCNI patients (Table 1), we found that plasmablasts were detected only in subjects who had OCBs. Further, we found increased numbers of DCs and pDCs not only in MS but also in SCNI. These results show that t-SNE projections do not 

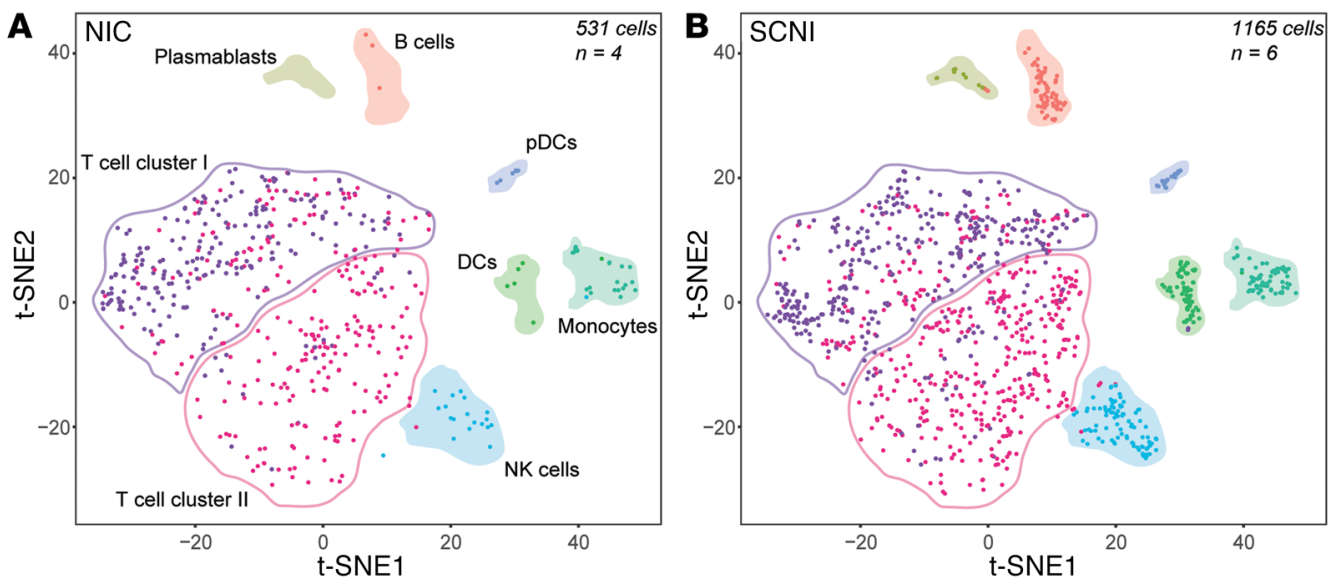

Figure 2. Cellular composition of CSF samples in different disease stages of MS and controls. $t-S N E$ projections of CSF samples from subjects with NIC (A), SCNI (B), MS (C), and Enc (D). Clusters were defined as in Figure 1B but blood cells were removed. CD4 ${ }^{+}$and CD8 ${ }^{+} \mathrm{T}$ cells are colored according to the index-sorting information obtained by flow cytometry.
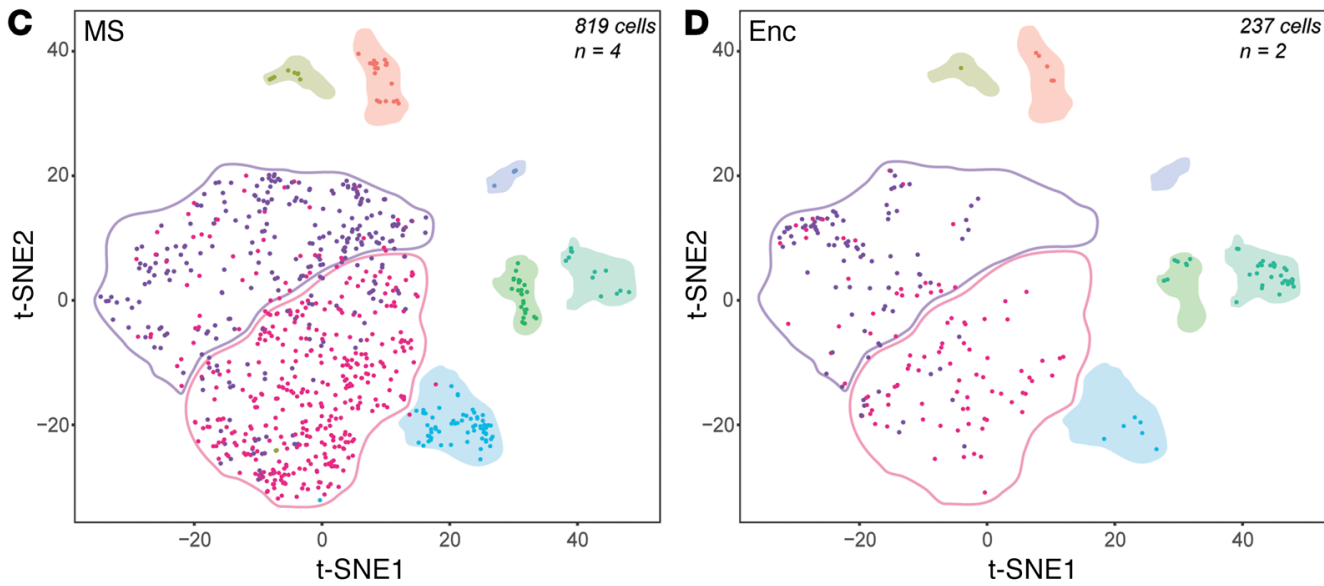

distinguish different stages of disease, except for the presence of plasmablasts, which are strictly correlated with OCBs and are already a distinct feature of subjects with SCNI.

Clonal expansions of $T$ cells and plasmablasts. In addition to clustering CSF cells according to their genome-wide expression profiles, our approach provides information about the antigen-specific, paired $\alpha: \beta$ TCR and H:L BCR chains expressed by individual lymphocytes. This enabled us to detect clonal $\mathrm{B}$ and $\mathrm{T}$ cell expansions in clusters containing $\mathrm{B}$ or $\mathrm{T}$ cells in the t-SNE projections (Figure 3, A and B). Strong clonal expansions were detectable in the plasmablast cluster of MS, where $90 \%$ of all clones were expanded, but also in SCNI, where $20 \%$ were expanded. Expanded $\mathrm{CD} 4{ }^{+}$and $\mathrm{CD}^{+}$clones were found predominantly in $\mathrm{T}$ cell cluster II. The numbers of identified nonexpanded and expanded $\mathrm{T}$ cell clones are listed in Table 2. Strong clonal expansions were also found in the $\mathrm{CD}^{+} \mathrm{T}$ cell population of all inflammatory cases (SCNI, MS, Enc), whereas lower percentages of expansions were observed in the $\mathrm{CD} 4^{+}$population. For example, $29 \%$ of all $\mathrm{CD}^{+}$but only $9 \%$ of all $\mathrm{CD}^{+}{ }^{+} \mathrm{T}$ cells from MS patients belonged to expanded clones, and a similar preponderance of expanded $\mathrm{CD}^{+}$cells was seen in SCNI and Enc (Table 2). Note that the ratios of expanded versus nonexpanded cells are given in percent independently for $\mathrm{CD} 4^{+}$and $\mathrm{CD} 8^{+}$cells. They are therefore not related to the absolute cell numbers or to CD4/CD8 ratios. Regarding the distribution of expanded $\mathrm{T}$ cells between clusters I and II, most $\mathrm{CD}^{+}$clones from SCNI subjects tended to group in the upper right region of cluster II, whereas clones from
MS patients were found predominantly in the lower right and central right region (Figure 4, A and B). A similarly uneven distribution is seen for $\mathrm{CD}^{+}$clones. Comparison of TCR sequences of CSF-resident $\mathrm{CD}^{+} \mathrm{T}$ cells with sequences of corresponding memory and naive $\mathrm{CD} 8^{+} \mathrm{T}$ cells from peripheral blood revealed clonal overlaps of expanded clones preferentially in SCNI and healthy subjects, whereas fewer overlaps were observed in MS patients (Supplemental Figure 1; supplemental material available online with this article; https://doi.org/10.1172/JCI128475DS1). Whether these differences represent statistical fluctuations or systematic differences of phenotypic properties remains to be determined in future investigations with larger numbers of patients and cells. Taken together, clonal expansions occur in all cellular compartments of adaptive immunity, namely B cells, $\mathrm{CD}^{+} \mathrm{T}$ cells, and, to a lesser extent, $\mathrm{CD} 4^{+} \mathrm{T}$ cells. In particular, such clonal expansions are a consistent and conspicuous feature observed in subjects with SCNI.

Differentially regulated transcripts in expanded versus nonexpanded $T$ cell clones. Clonal expansion is usually interpreted as evidence for pathogenic relevance of the expanded lymphocyte clones. Therefore, we compared normalized expression levels of differentially expressed genes related to $\mathrm{T}$ cell egress, tissue retention, inhibition, transcription factors, cytokines, and migration and activation of expanded and nonexpanded $\mathrm{CD}^{+} \mathrm{T}$ cell clones (Figure 5). The top panel of this heatmap shows expression of homing receptors and molecules involved in $\mathrm{T}$ cell egress, including CCR7, SELL (CD62L), TCF7 (TCF-1), and S1PR1. These 

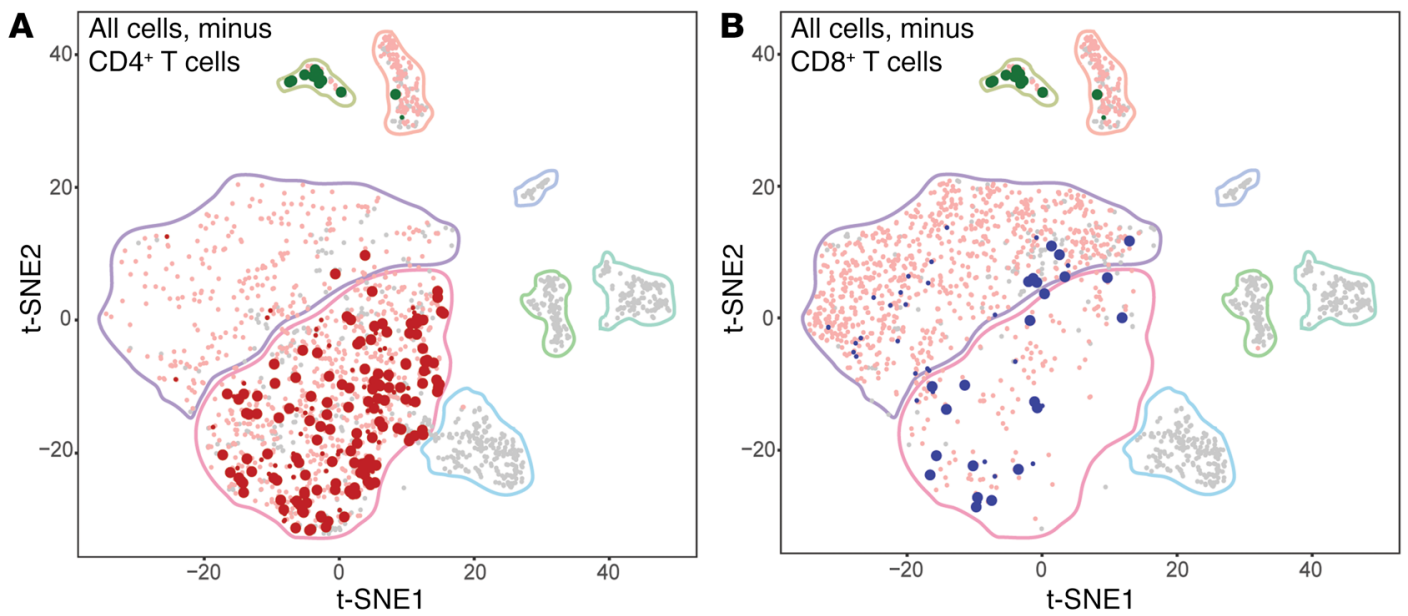

Figure 3. Analysis of clonally expanded lymphocyte cells. t-SNE projection of all CSF cells where either CD4+ (A) or CD8+ (B) cells were removed. Cells of the adaptive immune system with at least 1 detectable TCR or BCR chain are shown in light reddish color. Cells of the innate immune system are shown in

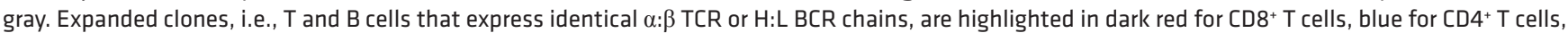
and green for B cells. Dot sizes correlate with clonal frequencies: normal-sized dots indicate that the clone was found 2 times; larger dots indicate that it was found 3 or more times.

markers are gradually downregulated from NIC, via nonexpanded cells from SCNI and MS subjects, to expanded clones from SCNI and MS subjects. In the latter case, all markers are downregulated, indicating a fully established $\mathrm{T}_{\mathrm{RM}}$ phenotype (10-12).

In addition, CD69 (second panel), which has been postulated as a marker of $\mathrm{T}_{\mathrm{RM}}$ as well as being an early activation marker $(13,14)$, is upregulated in the MS expanded $\mathrm{CD}^{+} \mathrm{T}$ cell clones but not in SCNI. Consistently, other tissue retention molecules, i.e., ITGAE (CD103), ITGA1 (CD49a), and CRTAM, which play an important role in $\mathrm{T}_{\mathrm{RM}}$ development (14), are upregulated in MS as compared with SCNI, but no significant differences are seen between expanded and nonexpanded clones.

Typical $\mathrm{T}_{\mathrm{RM}}$ gene signatures also include upregulation of inhibitors of T cell activation, including PDCD1 (PD-1), CD101, CTLA4 (third panel), and increased expression of CXCR6 (bottom panel), a recently identified key marker of $\mathrm{T}_{\mathrm{RM}}$ cells (14). Strikingly, our data again show upregulation of these molecules in the expanded $\mathrm{CD}^{+} \mathrm{T}$ cell population in MS but not in SCNI subjects. Further, this expression profile is consistent with upregulation of the key regulator of the universal $\mathrm{T}_{\mathrm{RM}}$ transcriptional program ZNF683 (Hobit), which causes downregulation of KLF2 (fourth panel) (15, 16), and finally downregulation of the egress-related transcripts. Such a pattern is not seen explicitly in SCNI.

The cytokine expression panel (fifth panel) resembles $\mathrm{T}_{\mathrm{RM}}$ characteristics in expanded $\mathrm{CD}^{+}$clones from MS patients and additional signs of $\mathrm{T}$ cell activation as indicated by GZMH, high levels of CXCR6 and CCR5, and proinflammatory cytokines including IFNG and IL-2 $(10,14,17)$. Other activation and migration markers, such as SLAMF7, FCRL6, ADGRE5 (CD97) (bottom panel), and HLA class II, were also upregulated in $\mathrm{CD}^{+} \mathrm{T}$ cells from $\mathrm{MS}$ patients. In SCNI, no increases or only minor increases of these markers were seen.

Similar, though not as concise, patterns are detected by comparison of expanded and nonexpanded $\mathrm{CD} 4^{+} \mathrm{T}$ cell clones (Supplemental Figure 2). As seen for $\mathrm{CD}^{+} \mathrm{T}$ cells, the bias toward $\mathrm{T}_{\mathrm{RM}}$ increases from NIC via SCNI to expanded clones in MS. Together, these find- ings indicate that expanded and nonexpanded $\mathrm{T}$ cell clones display different expression profiles. Markers for T cell egress, tissue retention, and inhibition together with the cytokine pattern suggest a $\mathrm{T}_{\mathrm{RM}}$ phenotype in expanded $\mathrm{T}$ cell clones from MS patients, particularly in the CD8 compartment. In MS, the expanded CD8 ${ }^{+} \mathrm{T}$ cells express markers of cellular activation and cytotoxic activity. Conspicuous clonal expansions are also present in SCNI, but - compared with MS - they show a less distinct phenotype and activation profile.

Recruitment of expanded $T_{R M} C D 8^{+}$cells into the CSF of MS patients. Because heatmaps only show average values of all cells, we next analyzed the strong downregulation of S1PR1 and upregulation of CXCR6 in single expanded $\mathrm{T}_{\mathrm{RM}} \mathrm{CD} 8^{+}$cells from different subject groups by violin plots (Figure 6, A and B). S1PR1 is significantly downregulated only in expanded $\mathrm{CD} 8^{+}$cells from MS patients, and CXCR6 is upregulated only in expanded cells from MS and Enc patients. CXCR6 is the sole receptor for CXCL16,

Table 2. Numbers of identified nonexpanded and expanded T cell clones

\begin{tabular}{lcccccccc} 
& \multicolumn{2}{c}{ NIC } & \multicolumn{2}{c}{ SCNI } & \multicolumn{2}{c}{ MS } & \multicolumn{2}{c}{ Enc } \\
& Non & Exp & Non & Exp & Non & Exp & Non & Exp \\
CD4 ${ }^{+} \alpha \beta$ T cells & 201 & & 319 & & 244 & & 78 & \\
Cells & 197 & 4 & 301 & 18 & 221 & 23 & 74 & 4 \\
$\%$ & $98 \%$ & $\mathbf{2 \%}$ & $94 \%$ & $\mathbf{6 \%}$ & $91 \%$ & $\mathbf{9 \%}$ & $95 \%$ & $\mathbf{5 \%}$ \\
CD8 ${ }^{+} \alpha \beta$ T cells & 208 & & 333 & & 324 & & 79 & \\
Cells & 204 & 4 & 283 & 50 & 230 & 94 & 57 & 22 \\
$\%$ & $98 \%$ & $\mathbf{2 \%}$ & $85 \%$ & $\mathbf{1 5 \%}$ & $71 \%$ & $\mathbf{2 9} \%$ & $72 \%$ & $\mathbf{2 8 \%}$
\end{tabular}

Total cell numbers and percentages of nonexpanded (Non) and clonally expanded (Exp) CD4 ${ }^{+}$and $C D 8^{+} T$ cells for each population. Percentages were normalized to the total numbers of cells within each individual CD4+ and $C D 8^{+}$population ( $\chi^{2}$ test: NIC, not significant; SCNI, $P=0.00009$; MS, $P=0.00001$; Enc, $P=0.00013$; results are significant at $P<0.05$ ). Boldface in the table represents the values of the larger dots in Figure 3. 

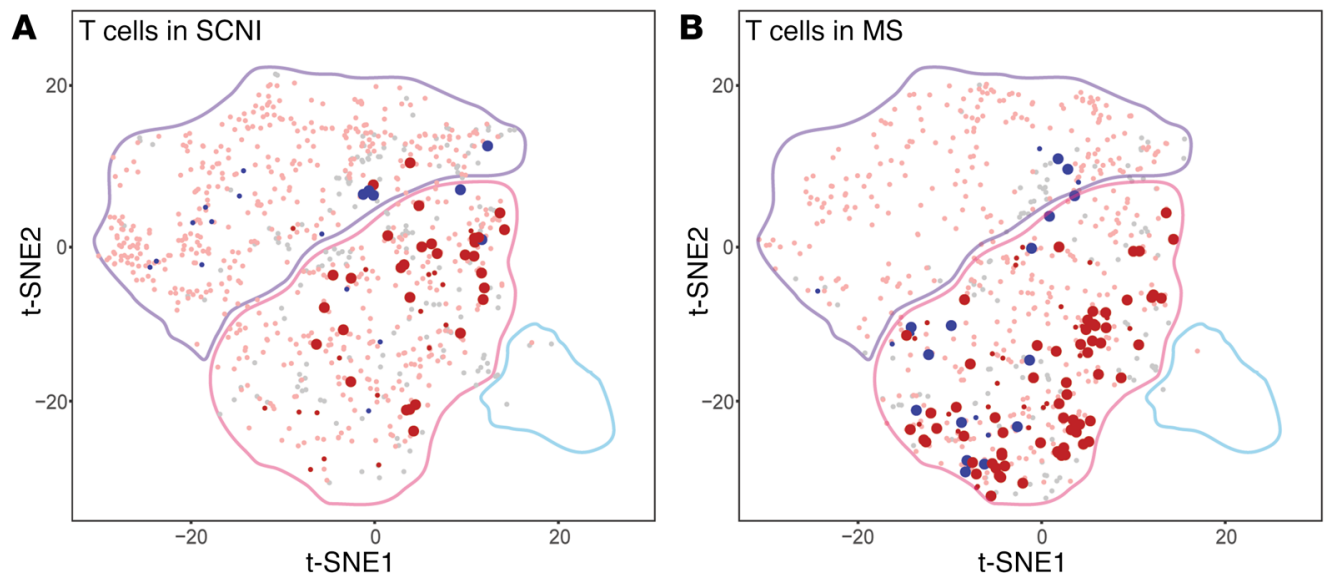

Figure 4. Analysis of clonally expanded T cells in SCNI and MS. $\mathrm{t}-\mathrm{SNE}$ projection of all CD8 ${ }^{+}$and CD4 ${ }^{+} T$ cells from subjects with SCNI (A) and MS (B). Expanded T cell clones that express identical $\alpha: \beta$ TCR are highlighted in dark red for $\mathrm{CD} 8^{+} \mathrm{T}$ cells and blue for $\mathrm{CD} 4^{+} \mathrm{T}$ cells. Dot sizes correlate with clonal frequencies: normal-sized dots indicate that the clone was found 2 times; larger dots indicate that it was found 3 or more times.

which can mediate lymphocyte recruitment, in particular of $\mathrm{CD}^{+} \mathrm{T}$ cells, and is induced by the proinflammatory cytokine IFNG (18). Here we found significant upregulation of CXCL16 in DCs and monocytes (Figure 6C) from all subject groups (Figure 6D). Notably, IFNG is also strongly upregulated in expanded $\mathrm{CD}^{+} \mathrm{T}$ cells of MS (Figure 5), whereas it is not upregulated in all other subject groups, including SCNI. Taken together, these findings indicate that the CXCR6-CXCL16 axis may be involved in the recruitment and maintenance of clonally expanded CD8 ${ }^{+}$ $\mathrm{T}$ cells in the CSF of MS patients.

Comparison of clonal expansions within monozygotic, MS-discordant twin pairs. We were able to obtain CSF from 4 MS-discordant twin pairs (Table 1). This allowed us to compare different disease conditions on a genetically identical background. Thus, in contrast to Figure 5, where data from all subjects were analyzed together, we now compared distinct twin pairs. In 2 twin pairs, the clinically unaffected twin had SCNI (Figure 7 and Supplemental Figure 3), whereas in the 2 other pairs, the clinically unaffected twin had no evidence of subclinical inflammation (NIC; Supplemental Figures 4 and 5). Thus, we compared the gene expression pattern of $\mathrm{CD}^{+}$ T cells individually for each pair: AR-MS versus AR-H, who later developed radiologically isolated syndrome, i.e., MRI-based evidence for dissemination in space (Figure 7); AU-MS versus AU-H (Supplemental Figure 3); AV-MS versus AV-H (healthy) (Supplemental Figure 4); and BJ-MS versus BJ-H (Supplemental Figure 5). The individual gene expression patterns fit to the average patterns shown in Figure 5 with signatures of $\mathrm{T}_{\mathrm{RM}}$ cells, expression of a panel of cytotoxic molecules, higher proinflammatory marker cytokines, and markers of activation including MHC class II. These patterns are particularly pronounced in expanded $\mathrm{CD}^{+} \mathrm{T}$ cells
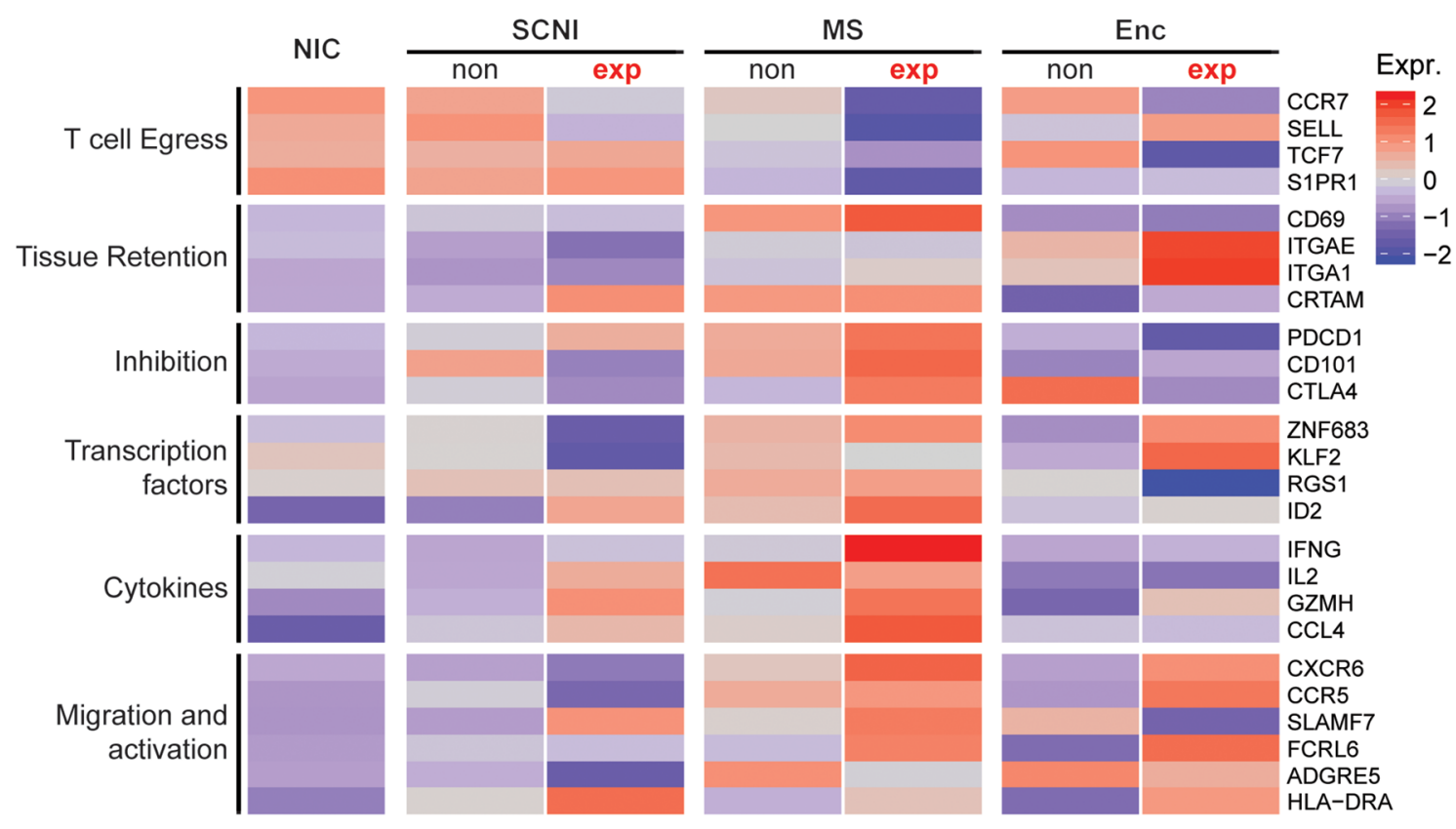

Figure 5. Heatmap of gene expression levels of selected function-associated genes in CD8+ $\mathbf{T}$ cells. CD8 ${ }^{+} T$ cells were selected based on flow cytometry staining for CD8 and presence of at least one TCR chain as determined by next-generation sequencing. Gene expression of 25 marker genes for homing, migration, and activation is shown for nonexpanded CD8 ${ }^{+} \mathrm{T}$ cells and expanded CD8 ${ }^{+} \mathrm{T}$ cell clones from SCNI, MS, and Enc subjects. No distinction is made for NIC, as the number of expanded clones is too low. Color scheme is based on Z score distribution from -2.5 (blue) to 2.5 (red). 
A

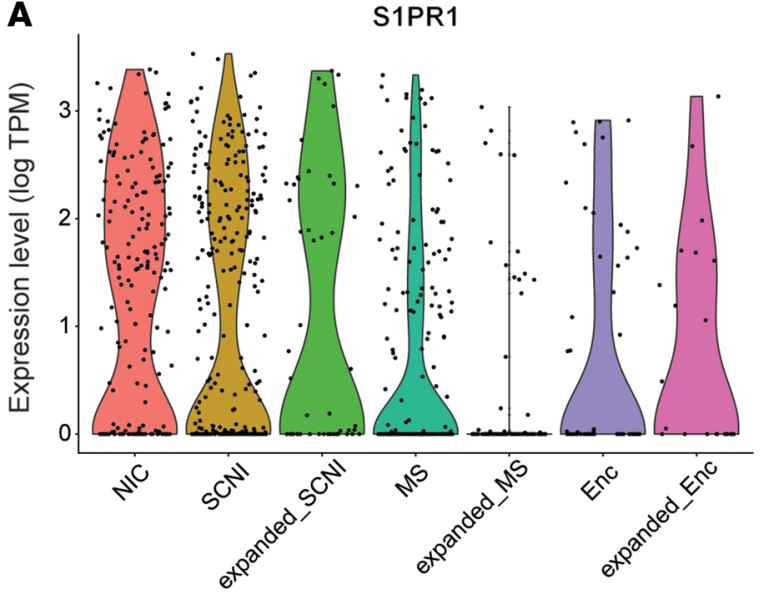

C

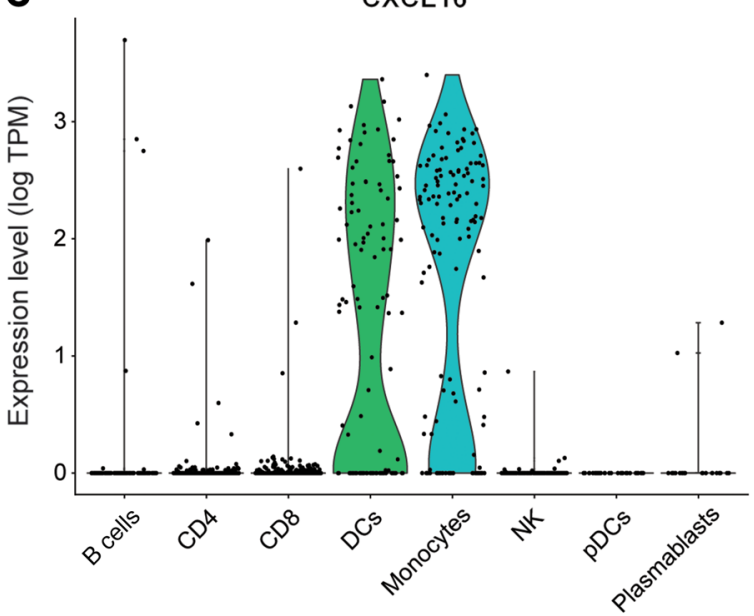

B

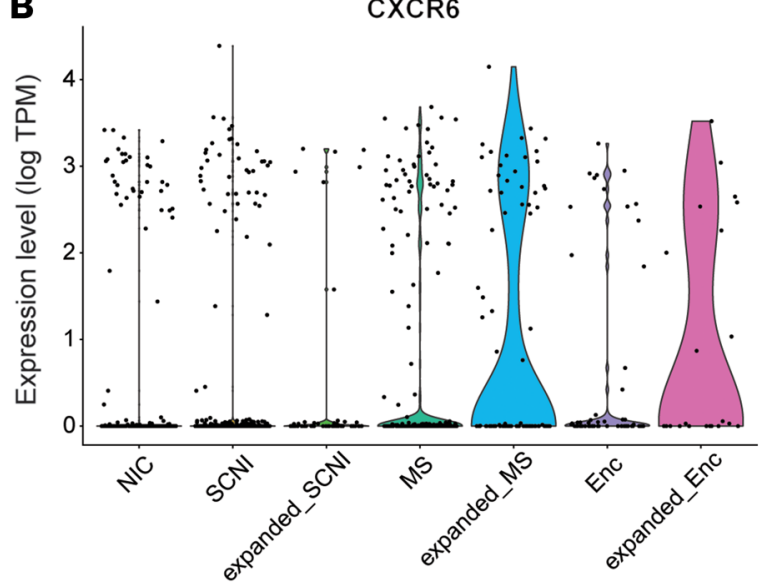

D

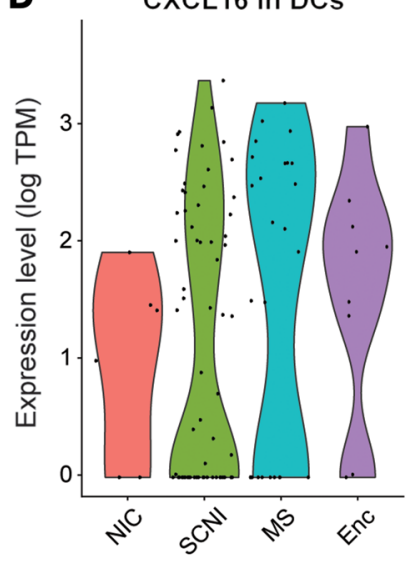

CXCL16 in Monocytes

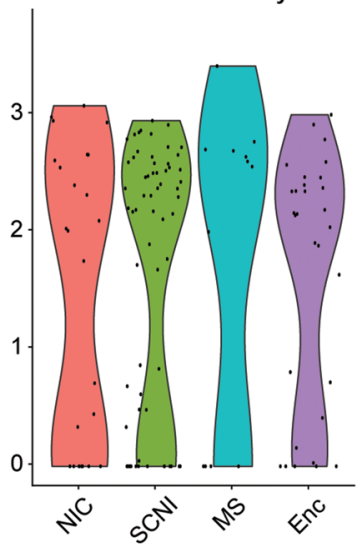

Figure 6. Violin plots show gene expression of $\mathrm{CD8}^{+} \mathbf{T}$ cells on the single-cell level. Each dot represents a single cell. Statistically significant gene expression is observed only if a violin-shaped fitting area can be calculated. (A) The homing marker S1PR1 is expressed on all T cells but is downregulated when a cell adopts a $T_{R M}$ phenotype. This is only the case for expanded CD8 ${ }^{+}$T cells from MS patients. (B) The $T_{\text {RM }}$ marker CXCR6 is upregulated only in expanded CD8 ${ }^{+} T$ cells from MS and Enc patients. (C) The marker CXCL16 is the sole ligand of CXCR6. It is upregulated only in DCs and monocytes. (D) CXCL16 is expressed in DCs (left panel) and monocytes (right panel) from all patient groups.

from MS patients as compared with nonexpanded cells, and with SCNI or healthy twins. This is remarkable since all MS patients received different medication (Table 1). The only exception is pair BJ-MS, BJ-H (Supplemental Figure 5), in whom the pattern of the teriflunomide-treated MS patient BJ-MS differs from those of all other probands. Together, these findings in genetically identical, yet disease-discordant twins support the notion that clonal activation and expansion, particularly of $\mathrm{CD} 8^{+} \mathrm{T}$ cells, is a distinct, very early event in the chain of pathogenic events leading from prodromal SCNI to clinically manifest MS.

\section{Discussion}

Here we investigated early cellular CSF profiles in the prodromal stage of MS in subjects with a maximally high familial risk of developing clinically manifest MS. We identified 8 subjects who were clinically unaffected but had an identical twin sibling who had clinically definite MS. Only 2 of them did not show any evidence of latent neuroinflammation, whereas 6 showed MRI signs of SCNI and 4 additionally showed OCBs. This allowed us to investigate SCNI using freshly isolated CSF cells for index sorting and sub- sequent scRNA-Seq, including identification of clonally distributed B and T cell antigen receptor chains at the single-cell level. Compared with traditional approaches that often focus on particular, predefined subsets and lineages of lymphocytes, scRNA-Seq provides an unbiased overview and therefore offers novel insights into the complexity of human (auto)immune reactions.

SCNI as defined here is not identical with conventional radiologically isolated syndrome (RIS). The concept of RIS is based on radiological criteria that have changed over time. According to the most recent criteria, the diagnosis of RIS requires at least $1 \mathrm{MRI}$ lesion in at least 2 predefined areas (19, 20). As RIS is usually discovered by chance, strict radiological criteria are required in order to distinguish neuroinflammatory MRI changes from those commonly observed in other conditions like migraine or ischemia. Rather than relying on chance detection, in our study we searched for SCNI in a cohort of subjects who had a maximal familial risk of developing MS. In this way we identified 6 clinically "healthy" co-twins who showed small MRI lesions (Table 1). It is noteworthy that these subjects represent a spectrum of SCNI changes (Table 1): two (AR-H and 


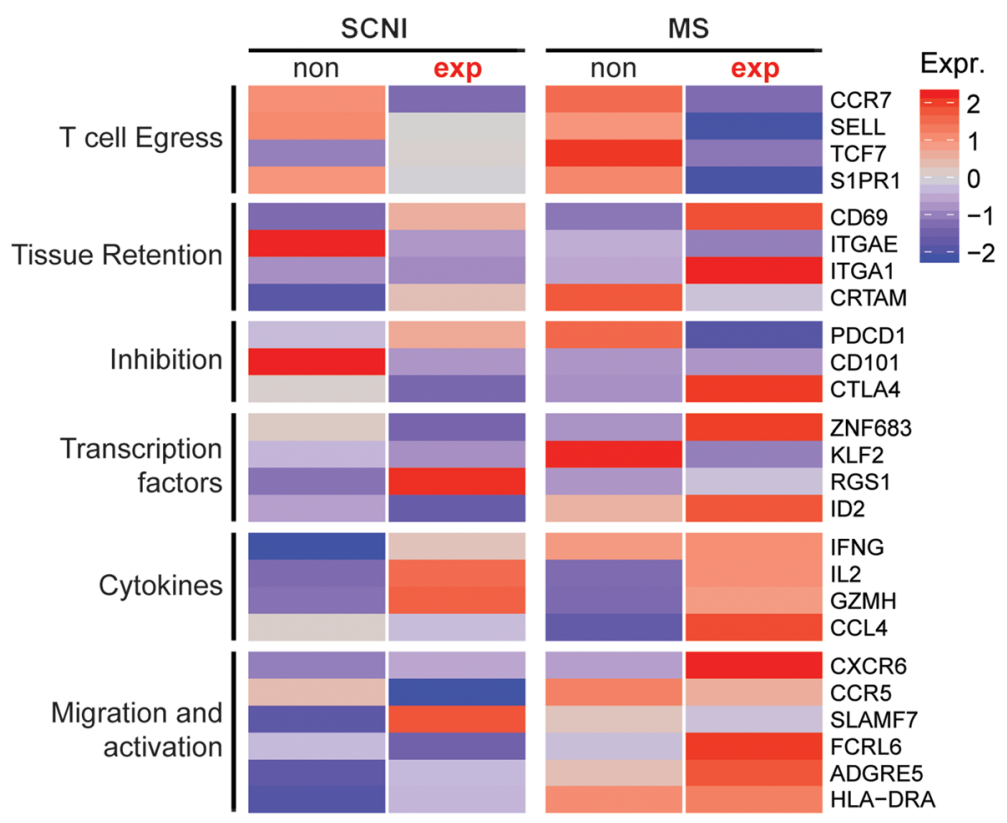

Figure 7. Heatmap of gene expression levels of nonexpanded and expanded CD8 ${ }^{+} \mathrm{T}$ cells from 1 monozygotic twin pair. Expression levels of the same genes as in Figure 5 are shown for the twin pair AR-H and AR-MS.

BF-H; Table 1) fulfilled the current RIS criteria of dissemination in space, whereas the other 4 SCNI subjects, 2 of whom had positive OCBs, did not fulfill the current RIS criteria and thus may be considered "pre-RIS." Indeed, one of the SCNI subjects (AR-H) meanwhile showed MRI evidence for dissemination in time (Table 1). Like conventional RIS, SCNI may be regarded as an early stage in the pathogenesis of MS, although it is impossible to know exactly when lesion initiation started.

One of the most conspicuous features we observed in our t-SNE projections of CSF cells from subjects with SCNI was the early and consistent presence of clonally expanded, activated $\mathrm{CD} 8^{+} \mathrm{T}$ cells. $\mathrm{CD} 8^{+}$cells have long been implicated in the pathogenesis of human MS because they predominate in MS brain lesions and show signs of clonal expansion, persistence, and pervasiveness, all of which support their pathogenic relevance $(3,21-28)$. However, $\mathrm{CD}^{+} \mathrm{T}$ cells have not been extensively studied in animal models, and therefore, they do not play a prominent role in the $\mathrm{CD}^{+} \mathrm{T}$ cell-centered scenario derived from classical experimental autoimmune encephalomyelitis models (29). Indeed, it has been argued that the $\mathrm{CD} 8^{+}$predominance in MS lesions might reflect the recruitment of bystander cells, and therefore a secondary event in the pathogenesis. Our findings strongly support the notion that clonal activation and expansion of $\mathrm{CD} 8^{+} \mathrm{T}$ cells represent crucial, early steps in the disease process.

We identified striking differences between expanded and nonexpanded $\mathrm{CD}^{+} \mathrm{T}$ cell clones. Regarding nonexpanded $\mathrm{T}$ cell clones, we did not observe much variation between NIC, SCNI, MS, and Enc subjects in the t-SNE projections. Slight differences were seen when we analyzed specific homing, migration, and activation markers. In striking contrast, we observed major alterations in $\mathrm{t}$-SNE projections and markers when we analyzed clonally expanded $\mathrm{T}$ cells, which were detected in all subjects with neuroinflamma- tion, although to a different extent. Thus, the percentages of expanded clones as compared with nonexpanded clones were about 2-fold higher in MS and Enc than in SCNI, and higher in SCNI than in NIC. In all conditions, $\mathrm{CD}^{+}{ }^{+} \mathrm{T}$ cell expansions were more frequent than $\mathrm{CD} 4^{+}$ expansions. In both populations, however, there were subtle differences between SCNI and MS in the t-SNE projections of the expanded clones, indicating altered cellular phenotypes. Because dimensional reductions were calculated on thousands of highly diverse genes, the resulting clusters may not reflect the classical lineages that are defined by a few selected markers.

Gene expression analysis of markers related to migration, homing, and activation of $\mathrm{CD} 8^{+} \mathrm{T}$ cells revealed that expression of egress markers (S1PR1, CCR7, SELL, TCF7) was normal in NIC but strongly downregulated in expanded $\mathrm{CD} 8^{+} \mathrm{T}_{\mathrm{RM}}$ cell clones from MS patients. In nonexpanded MS cells, they were weakly downregulated, suggesting that this population is sensing the inflammatory milieu and is possibly "on the road" to adopting a $\mathrm{T}_{\mathrm{RM}}$ phenotype. The expression levels of egress markers in SCNI reveal that nonexpanded $\mathrm{CD} 8^{+} \mathrm{T}$ cells are indistinguishable from NIC cells. Strikingly, expanded $\mathrm{CD} 8^{+} \mathrm{T}$ cells from SCNI, though fewer in number than expanded $\mathrm{CD} 8^{+} \mathrm{T}$ cells from MS, downregulated CCR7 and SELL and upregulated proinflammatory cytokines, indicating that they are in transition to an effector phenotype. This is also reflected by different positions in the t-SNE projections (Figure 4, A and B). Comparison of egress markers and $\mathrm{t}$-SNE projections therefore illustrates the gradual transition from $\mathrm{a}_{\mathrm{CM}}$ to an effector phenotype, moving from NIC and nonexpanded SCNI to expanded T cell SCNI and nonexpanded MS, to a fully established $\mathrm{T}_{\mathrm{RM}}$ phenotype of $\mathrm{CD} 8^{+} \mathrm{T}$ cells in definite MS. This interpretation is supported by the gradual upregulation of inhibition and retention markers (such as PDCD1 or CD69), cytokines, and activation markers (such as IFNG or CXCR6), moving from NIC and nonexpanded SCNI, to expanded SCNI and nonexpanded MS, and finally to definite MS. This pattern is compatible with a phenotype change of $C D 8^{+} T$ cells from $T_{C M}$ to $T_{R M}$ during the course of the disease.

Four of the six SCNI subjects had positive CSF OCBs. This is in agreement with numerous previous reports that OCBs represent an early immunological marker of neuroinflammation and indeed serve as a prognostic marker in subjects with RIS (30). The presence of OCBs was strictly correlated with the presence and expansion of plasmablasts in our t-SNE projection. This is consistent with previous observations that plasmablasts are characteristic components of the B cell compartment in $\operatorname{MS} \operatorname{CSF}(31,32)$, and supports our previous observation that intrathecal $\mathrm{B}$ cells are a cellular source of OCBs (33), which at least in some cases were shown to be involved in removal of debris from cells that died by prior events (34). Together, our data suggest that deleterious inflammatory events may already be ongoing at a cryptic stage of the disease, possibly even earlier than the SCNI stage investigated here.

Extensive analyses of intrathecal B cell clonal pedigrees suggested an ongoing intrathecal antigen-driven B cell maturation process in MS, including immunoglobulin class switching and 
somatic hypermutation (35-37). These processes likely depend on help by $\mathrm{CD}^{+} \mathrm{T}$ cells. However, our scRNA-Seq analyses of CSF $\mathrm{CD}^{+} \mathrm{T}$ cells did not reveal any distinct signatures of known $\mathrm{CD} 4^{+}$ $\mathrm{T}$ cell lineages such as $\mathrm{T}$ follicular helper cells, regulatory $\mathrm{T}$ cells, Th1, Th2, or Th17 effector cells, which are usually defined by flow cytometry. This by no means implies that $\mathrm{CD} 4^{+} \mathrm{T}$ cells are not crucially involved. However, with the introduction of scRNA-Seq, the borders between traditional cell lineages are beginning to blur, and an unexpected complexity and dynamic nature of the cellular immune system are beginning to emerge $(38,39)$.

A still unanswered key question in MS pathogenesis is how putatively autoreactive lymphocytes are recruited to the CNS and which target cells they communicate with. It has long been known that $\mathrm{T}$ cells survey the brain parenchyma also in noninflammatory conditions (40), and recently it has been shown that many of them are $\mathrm{T}_{\mathrm{RM}}$ cells (41). Here we found that expanded CD8 ${ }^{+} \mathrm{T}$ cells from MS and Enc patients strongly upregulated CXCR6. CXCR6 has been implicated in various human diseases $(17,42-44)$, and notably, it has a significant role in recruiting activated $\mathrm{CD}^{+}$, but not $\mathrm{CD}^{+}$, $\mathrm{T}$ cells, under pathological conditions $(42,43)$. Its only ligand is CXCL16. Strikingly, we detected highly elevated levels of CXCL16 transcription in monocytes and DCs in the CSF. For CD $4^{+}$ T cells, we also observed upregulation of CXCR6 predominantly in expanded clones of SCNI and MS subjects. This might also be triggered by mononuclear phagocytes and/or DCs serving as antigen-presenting cells. Consistent with earlier reports $(45,46)$, we observed DCs and pDCs already in the CSF of NIC with a marked predominance of myeloid DCs over pDCs, but cell numbers were significantly increased in the CSF of patients with neuroinflammatory diseases, such as MS. This is not yet an ultimate proof of a functional interaction of $\mathrm{CD} 8^{+} \mathrm{T}$ cells with mononuclear phagocytes and/or DCs, but it may trigger further investigations.

An obvious limitation of our study is the small sample size. For example, we did not include subjects with clinically isolated syndrome because they are usually sampled in close relation to clinical activity. In our study, all subjects were sampled outside clinical activity, as this could turn out to be a significant confounding factor that hampers comparability of data and needs to be addressed in future studies with larger cohorts. The same applies to the potential confounding effects of various MS treatments. In contrast to the subjects with SCNI, who had never been exposed to any immunomodulatory therapy, the group of MS patients was heterogeneous with regard to treatment. Surprisingly, however, there were no significant differences in the overall CSF cell populations, clonal expansions, and gene expression levels of the MS patients irrespective of their diverse treatments. The only significant deviation from the reasonably conserved overall expression pattern was seen in MS patient BJ-MS, who was under teriflunomide treatment, which inhibits lymphocyte proliferation and therefore changes gene expression patterns and phenotypes. Obviously, these treatment-related initial findings need validation in larger cohorts.

Our results provide a first glimpse into the complexity of CSF cells at a very early stage of neuroinflammation as it occurs in clinically healthy subjects who are at a maximally high familial risk because they have a monozygotic co-twin affected by MS. In these subjects, we observed evidence for early involvement of the major components of the adaptive immune system, B cells, $\mathrm{CD}^{+} \mathrm{T}$ cells, and $\mathrm{CD}^{+} \mathrm{T}$ cells. Both in SCNI and in MS, conspicuous changes were observed in clonally expanded $\mathrm{CD} 8^{+} \mathrm{T}$ cells, though these changes were more pronounced in MS than in SCNI. The observed alterations in gene expression levels suggest that activation and clonal expansion of $\mathrm{CD}^{+} \mathrm{T}$ cells are not just a late epiphenomenon but rather reflect early mechanisms of MS pathogenesis. Expanded $\mathrm{CD}^{+} \mathrm{T}$ cell clones show a $\mathrm{T}_{\mathrm{RM}}$ phenotype and may be assumed to relate directly to disease progression as seen in tumors and infections $(7,8,10)$. It is tempting to speculate that expanded $\mathrm{CD}^{+}$clones might also play a major role in CNS lesions, where they are the dominant lymphocyte population, persist, and are shared between CNS and CSF (22-27). Although our cohort is small and should be enlarged for drawing final conclusions, our results underline the need to study antigens and communication partners of intrathecally expanded $\mathrm{CD}^{+} \mathrm{T}$ cell clones in much greater detail. These results have implications not only for the pathogenesis but also for the therapy of MS.

\section{Methods}

Study subjects and procedures. Twins were recruited in Germany. Inclusion criteria for study participation were met for monozygotic twins with an MS diagnosis according to the revised McDonald criteria (20). Monozygotic twin pairs with clinical discordance for MS visited the outpatient department at the Institute of Clinical Neuroimmunology, Munich, for a detailed interview, neurological examination, MRI investigations, and optional CSF sampling. Twins either volunteered for CSF sampling or were specifically offered CSF sampling if suspicious lesions were detected on MRI. For inclusion in the present analysis, CSF samples had to be available of either both co-twins or the clinically healthy co-twin only, resulting in 4 monozygotic twin pairs and 4 additional clinically healthy co-twins with signs of SCNI in MRI and/or CSF. Zygosity was confirmed by genotyping of 17 highly polymorphic microsatellite markers and by next-generation sequencing of 33 SNPs. CSF samples from control subjects with encephalitis (Enc) and noninflammatory controls (NIC) were provided during routine diagnostic testing or serial CSF collection to treat idiopathic intracranial hypertension. All twins underwent MR imaging on a 3 Tesla MR scanner (Magnetom Skyra, Siemens Healthineers) using a 20-channel phased-array head and neck coil. The sequence protocol included a 3D-FLAIR (TI 1800 $\mathrm{ms}$, TR $5000 \mathrm{~ms}$, TE $388 \mathrm{~ms}$, flip angle $90^{\circ}$; $1.0 \mathrm{~mm}^{3}$ isotropic voxels) and a 3D T1-weighted sequence using a 3D magnetization-prepared rapid-acquisition gradient-echo (MP-RAGE) sequence (TR $1600 \mathrm{ms,}$ TE $2.15 \mathrm{~ms}$, flip angle $9^{\circ} ; 1.0 \mathrm{~mm}^{3}$ isotropic voxels).

Flow cytometry single-cell index sorting. Fresh CSF and blood samples were processed within 1 hour after collection. CSF samples (3-6 $\mathrm{mL}$ ) were centrifuged at $300 \mathrm{~g}$ for 10 minutes and $\mathrm{CD} 4^{+}$cells isolated using the EasySep human CD4 Positive Selection Kit II (STEMCELL Technologies) according to the manufacturer's instructions. In parallel, non-CD4 ${ }^{+}$cells were stained for the following lymphocyte cell surface markers: CD3 (eBioscience, clone OKT3; diluted 1:50), CD8 (BioLegend, clone SK1; diluted at 1:50), CD56 (BioLegend, clone HCD56; diluted 1:40), CD19 (BioLegend, clone HIB19; diluted at 1:40), CD27 (BioLegend, clone O323; diluted 1:40), CD38 (eBioscience, clone HB7; diluted 1:40), and Fc receptor blocking (Miltenyi Biotec) in a total volume of $100 \mu \mathrm{L}$ PBS with 2\% FBS. After incubation for 30 minutes at $4^{\circ} \mathrm{C}$, both $\mathrm{CD} 4^{+}$and non-CD $4^{+}$cells were washed twice, resuspended 
in $300 \mu \mathrm{L}$ of the above buffer, and single-cell-sorted using a FACSAria Fusion (BD Biosciences) sorter. Single cells were sorted only according to their forward and side scatter properties, and no further gates were used to keep the ratios between all non-CD4 ${ }^{+}$cells unchanged. Cells were sorted into lysis buffer in 96-well plates using index sorting. Index sorting enabled us to sort all single cells while retaining the complete phenotype of every single cell sorted into the plate. For profiling of blood lymphocytes, PBMCs were isolated using Ficoll-Paque density gradient centrifugation. Single-cell suspensions were stained using the same markers as described above for $\mathrm{CD}^{+}$cells plus antiCD4 (BioLegend, clone SK3; diluted 1:25). Then, single CD4 ${ }^{+} \mathrm{T}$ cells $\left(\mathrm{CD}^{+} \mathrm{CD} 4^{+}\right), \mathrm{CD}^{+} \mathrm{T}$ cells $\left(\mathrm{CD}^{+} \mathrm{CD}^{+}\right)$, B cells $\left(\mathrm{CD} 3^{-} \mathrm{CD} 19^{+}\right)$, and $\mathrm{CD}^{-}{ }^{-} \mathrm{CD}^{-}{ }^{-}$cells were sorted into $96-$-well plates.

scRNA-Seq. The Smart-Seq2 protocol was performed on sorted single cells as described previously (47), with minor modifications. Briefly, PCR preamplification products were purified using Ampure $\mathrm{XP}$ beads in a 0.6:1 ratio. For the tagmentation reaction (48), 0.8 ng DNA was used as input. Then, PCR purification was carried out using Ampure XP beads in a 0.75:1 ratio. Multiplex sequencing of 96 single-cell libraries was performed on a Hiseq 1500 lane in 150bp paired-end mode, giving an average sequence depth of 2 million reads per cell. A total of 3362 CSF cells and 384 PMBCs were sequenced, and 2752 and 332 passed quality control. scRNA-Seq raw data were deposited in the NCBI's Sequence Read Archive database (SRA), and processed gene expression data can be accessed from the Gene Expression Omnibus (GEO) database under accession numbers SRP180896 and GSE127969.

scRNA-Seq data analyses. Short sequencing reads were aligned to the UCSC hg38 transcriptome using HISAT2. These alignments were used as input in featureCounts to count mapped reads in all samples. As quality control steps, we removed transcripts detected in fewer than 3 cells and kept only cells with 200 to 6000 detected transcripts. Further, we disregarded cells in which the proportion of mitochondrial transcripts was higher than $5 \%$. Following visual inspection, we further discarded cells located in a cluster characterized by mitochondrial and ribosomal gene expression. Transcripts per million (TPM) data were log-transformed $[\log (\mathrm{TPM}+1)]$ for all downstream analyses. Detection of highly variable genes, unbiased graph-based clustering of single-cell data, and identification of markers for each cluster were performed with Seurat (49). See Supplemental Methods (online) for more details, including the Seurat R script used to analyze the single-cell data. In addition, scRNA-Seq data were aligned to the TCR and Ig genes. The sorted reads were subjected to MiGECCdrBlast (https://migec.readthedocs.io) for extraction of TCR and Ig chains, leading to the identification of CDR3 sequences of TCR and BCR chains. To compare single-T cell repertoires from CSF with $\mathrm{T}$ cells from peripheral blood, we analyzed the TCR repertoire of T cells present in $14 \mathrm{~mL}$ blood collected into EDTA containing tubes as described previously (50).
Statistics. The $\chi^{2}$ test was used to assess the differences in size of both nonexpanded and expanded T cells in each of the study groups. A $P$ value less than 0.05 was considered statistically significant.

Study approval. The study was approved by the local ethics committee of the Ludwig Maximilian University of Munich, and all participants gave written informed consent, according to the principles of the Declaration of Helsinki.

\section{Author contributions}

EB, LAG, and JH share first authorship. EB and LAG both contributed to study design and, as EB also performed bioinformatics analysis, analyzed data and contributed to writing, he is listed first. See below for more detailed contributions. EB, LAG, RH, and $\mathrm{KD}$ designed the study and experiments. EB and JH performed flow cytometry experiments, PCR, and sample preparation for next-generation sequencing analysis. SK and HB performed Illumina next-generation sequencing. EB performed bioinformatics analysis. LAG, AFH, FB, TK, and RH characterized and contributed patients' samples. BEW performed MRI examinations and analyzed data. KD, RH, and EB analyzed data and wrote the manuscript with contributions of all other authors. All authors reviewed and approved the manuscript.

\section{Acknowledgments}

We are grateful to all subjects who participated in this study. We thank Edgar Meinl and Naoto Kawakami for comments on the manuscript, Nicolaus König for valuable support, and Katja Anslinger for zygosity determination, and acknowledge the Core Facility Flow Cytometry unit at the Biomedical Center, Ludwig Maximilian University of Munich, for providing equipment. The study was supported by the German Research Council through CRC128-A5, DO 420/3-1 DACH, the Munich Cluster for Systems Neurology (SyNergy), the Dr. Leopold and Carmen Ellinger Foundation, the Gemeinnützige Hertie Stiftung, the national division of the German MS Society (DMSG), the Bavarian Association of the German MS society (DMSG-Landesverband Bayern), the Federal Ministry of Education and Research (BMBF) organization Krankheitsbezogenes Kompetenznetz Multiple Sklerose, and the association Verein zur Therapieforschung für MS Kranke e.V. FB is supported by the National Institute for Health Research Biomedical Research Centre at University of College London Hospitals.

Address correspondence to: Klaus Dornmair or Eduardo Beltrán, Institut für Klinische Neuroimmunologie, Biomedical Center - LMU, Großhaderner Strasse 9, Room N.B. 03.013 (KD), Room N.B. 03.024A (EB), 82152 Planegg-Martinsried, Munich, Germany. Phone: 49.89.2180.71664; Email: Klaus.Dornmair@ med.uni-muenchen.de (KD). Phone: 49.89.2180.71671; Email: Eduardo.Beltran@med.uni-muenchen.de (EB).

\footnotetext{
1. Dendrou CA, Fugger L. Immunomodulation in multiple sclerosis: promises and pitfalls. Curr Opin Immunol. 2017;49:37-43.

2. Hohlfeld R, Dornmair K, Meinl E, Wekerle H. The search for the target antigens of multiple sclerosis, part 1: autoreactive $\mathrm{CD}^{+} \mathrm{T}$ lymphocytes as pathogenic effectors and therapeutic targets. Lancet Neurol. 2016;15(2):198-209.
}

3. Hohlfeld R, Dornmair K, Meinl E, Wekerle H. The search for the target antigens of multiple sclerosis, part 2: $\mathrm{CD}^{+} \mathrm{T}$ cells, B cells, and antibodies in the focus of reverse-translational research. Lancet Neurol. 2016;15(3):317-331.

4. Reich DS, Lucchinetti CF, Calabresi PA. Multiple sclerosis. N Engl J Med. 2018;378(2):169-180.

5. Papalexi E, Satija R. Single-cell RNA sequencing to explore immune cell heterogeneity. Nat Rev Immunol. 2018;18(1):35-45.

6. Stubbington MJT, Rozenblatt-Rosen O, Regev A, Teichmann SA. Single-cell transcriptomics to explore the immune system in health and disease. Science. 2017;358(6359):58-63.

7. Molodtsov A, Turk MJ. Tissue resident CD8 memory $\mathrm{T}$ cell responses in cancer and autoim- 
munity. Front Immunol. 2018;9:2810.

8. Park CO, Kupper TS. The emerging role of resident memory $\mathrm{T}$ cells in protective immunity and inflammatory disease. Nat Med. 2015;21(7):688-697.

9. Kivisäkk P, et al. Human cerebrospinal fluid central memory $\mathrm{CD} 4^{+} \mathrm{T}$ cells: evidence for trafficking through choroid plexus and meninges via P-selectin. Proc Natl Acad Sci US A. 2003;100(14):8389-8394.

10. Amsen D, van Gisbergen KPJM, Hombrink P, van Lier RAW. Tissue-resident memory T cells at the center of immunity to solid tumors. Nat Immunol. 2018;19(6):538-546.

11. Mackay LK, Kallies A. Transcriptional regulation of tissue-resident lymphocytes. Trends Immunol. 2017;38(2):94-103.

12. Matloubian M, et al. Lymphocyte egress from thymus and peripheral lymphoid organs is dependent on S1P receptor 1. Nature. 2004;427(6972):355-360.

13. Cibrián D, Sánchez-Madrid F. CD69: from activation marker to metabolic gatekeeper. Eur J Immunol. 2017;47(6):946-953.

14. Kumar BV, et al. Human tissue-resident memory $T$ cells are defined by core transcriptional and functional signatures in lymphoid and mucosal sites. Cell Rep. 2017;20(12):2921-2934.

15. Mackay LK, et al. Hobit and Blimp1 instruct a universal transcriptional program of tissue residency in lymphocytes. Science. 2016;352(6284):459-463.

16. Skon CN, Lee JY, Anderson KG, Masopust D, Hogquist KA, Jameson SC. Transcriptional downregulation of S1pr1 is required for the establishment of resident memory $\mathrm{CD}^{+} \mathrm{T}$ cells. Nat Immunol. 2013;14(12):1285-1293.

17. Zaid A, et al. Chemokine receptor-dependent control of skin tissue-resident memory $\mathrm{T}$ cell formation. J Immunol. 2017;199(7):2451-2459.

18. van Lieshout AW, et al. Regulation of CXCL16 expression and secretion by myeloid cells is not altered in rheumatoid arthritis. Ann Rheum Dis. 2009;68(6):1036-1043.

19. De Stefano N, et al. Radiologically isolated syndrome or subclinical multiple sclerosis: MAGNIMS consensus recommendations. Mult Scler. 2018;24(2):214-221.

20. Thompson AJ, et al. Diagnosis of multiple sclerosis: 2017 revisions of the McDonald criteria. Lancet Neurol. 2018;17(2):162-173.

21. Friese MA, Fugger L. Autoreactive $\mathrm{CD} 8^{+} \mathrm{T}$ cells in multiple sclerosis: a new target for therapy? Brain. 2005;128(pt 8):1747-1763.

22. Machado-Santos J, et al. The compartmentalized inflammatory response in the multiple sclerosis brain is composed of tissue-resident CD8+ T lymphocytes and B cells. Brain 2018;141(7):2066-2082.

23. Skulina C, et al. Multiple sclerosis: brain-infiltrating CD8+ T cells persist as clonal expansions in the cerebrospinal fluid and blood. Proc Natl Acad Sci U S A. 2004;101(8):2428-2433.

24. van Nierop GP, et al. Phenotypic and functional characterization of $\mathrm{T}$ cells in white matter lesions of multiple sclerosis patients. Acta Neuropathol. 2017;134(3):383-401.

25. Held K, et al. $\alpha \beta \mathrm{T}$-cell receptors from multiple sclerosis brain lesions show MAIT cell-related features. Neurol Neuroimmunol Neuroinflamm. 2015;2(4):e107.

26. Junker A, et al. Multiple sclerosis: T-cell receptor expression in distinct brain regions. Brain. 2007;130 (pt 11):2789-2799.

27. Salou M, et al. Expanded CD8 T-cell sharing between periphery and CNS in multiple sclerosis. Ann Clin Transl Neurol. 2015;2(6):609-622.

28. Babbe $\mathrm{H}$, et al. Clonal expansions of CD8(+) T cells dominate the $\mathrm{T}$ cell infiltrate in active multiple sclerosis lesions as shown by micromanipulation and single cell polymerase chain reaction. JExp Med. 2000;192(3):393-404.

29. Lassmann H. Pathogenic mechanisms associated with different clinical courses of multiple sclerosis. Front Immunol. 2018;9:3116.

30. Lebrun C, Kantarci OH, Siva A, Pelletier D, Okuda DT, RIS Consortium. Anomalies characteristic of central nervous system demyelination: radiologically isolated syndrome. Neurol Clin. 2018;36(1):59-68.

31. Cepok $\mathrm{S}$, et al. Short-lived plasma blasts are the main B cell effector subset during the course of multiple sclerosis. Brain. 2005;128(pt 7):1667-1676

32. Michel L, Touil H, Pikor NB, Gommerman JL, Prat A, Bar-Or A. B cells in the multiple sclerosis central nervous system: trafficking and contribution to CNS-compartmentalized inflammation. Front Immunol. 2015;6:636.

33. Obermeier B, et al. Matching of oligoclonal immunoglobulin transcriptomes and proteomes of cerebrospinal fluid in multiple sclerosis. $\mathrm{Nat}$ Med. 2008;14(6):688-693.

34. Brändle SM, et al. Distinct oligoclonal band antibodies in multiple sclerosis recognize ubiquitous self-proteins. Proc Natl Acad Sci U S A. 2016;113(28):7864-7869.

35. Beltrán E, et al. Intrathecal somatic hypermutation of IgM in multiple sclerosis and neuroinflammation. Brain. 2014;137(pt 10):2703-2714. 36. Palanichamy A, et al. Immunoglobulin class- switched B cells form an active immune axis between CNS and periphery in multiple sclerosis. Sci Transl Med.2014;6(248):248ra106.

37. Stern JN. B cells populating the multiple sclerosis brain mature in the draining cervical lymph nodes. Sci Transl Med. 2014;6(248):248ra107.

38. Neu KE, Tang Q, Wilson PC, Khan AA. Single-cell genomics: approaches and utility in immunology. Trends Immunol. 2017;38(2):140-149.

39. Nguyen A, Khoo WH, Moran I, Croucher PI, Phan TG. Single cell RNA sequencing of rare immune cell populations. Front Immunol. 2018;9:1553.

40. Ransohoff RM, Engelhardt B. The anatomical and cellular basis of immune surveillance in the central nervous system. Nat Rev Immunol. 2012;12(9):623-635.

41. Smolders J, et al. Tissue-resident memory T cells populate the human brain. Nat Commun. 2018;9(1):4593.

42. Günther C, Carballido-Perrig N, Kaesler S, Carballido JM, Biedermann T. CXCL16 and CXCR6 are upregulated in psoriasis and mediate cutaneous recruitment of human $\mathrm{CD} 8^{+} \mathrm{T}$ cells. J Invest Dermatol. 2012;132(3 pt 1):626-634.

43. Sato T, et al. Role for CXCR6 in recruitment of activated CD8+ lymphocytes to inflamed liver. JImmunol. 2005;174(1):277-283.

44. van der Voort R, et al. Elevated CXCL16 expression by synovial macrophages recruits memory T cells into rheumatoid joints. Arthritis Rheum. 2005;52(5):1381-1391.

45. de Graaf MT, et al. Central memory $\mathrm{CD}^{+}{ }^{+} \mathrm{T}$ cells dominate the normal cerebrospinal fluid. Cytometry B Clin Cytom. 2011;80(1):43-50.

46. Pashenkov M, Huang YM, Kostulas V, Haglund M, Söderström M, Link H. Two subsets of dendritic cells are present in human cerebrospinal fluid. Brain. 2001;124(pt 3):480-492.

47. Picelli S, Faridani OR, Björklund AK, Winberg G, Sagasser S, Sandberg R. Full-length RNA-seq from single cells using Smart-seq2. Nat Protoc. 2014;9(1):171-181.

48. Baym M, Kryazhimskiy S, Lieberman TD, Chung H, Desai MM, Kishony R. Inexpensive multiplexed library preparation for megabase-sized genomes. PLoS One. 2015;10(5):e0128036.

49. Butler A, Hoffman P, Smibert P, Papalexi E, Satija R. Integrating single-cell transcriptomic data across different conditions, technologies, and species. Nat Biotechnol. 2018;36(5):411-420.

50. Beltrán E, et al. Shared T cell receptor chains in blood memory $\mathrm{CD}^{+} \mathrm{T}$ cells of narcolepsy type 1 patients. JAutoimmun. 2019;100:1-6. 